\title{
A randomized, double-blind clinical trial of a herbal formulation (GlycaCare-II) for the management of type 2 diabetes in comparison with metformin
}

Muhammed Majeed ${ }^{1,2}$, Anju Majeed ${ }^{1}, K$ Kalyanam Nagabhusahnam² ${ }^{2}$ Lakshmi Mundkur $^{1}$ and Shaji Paulose ${ }^{\text {* }^{*}}$

\begin{abstract}
Background: Type 2 diabetes mellitus (T2DM) is a major public health concern with growing prevalence with multiple debilitating complications. GlycaCare-II is a proprietary herbal formulation supplement for T2DM containing extracts of Cinnamomum cassia, Momordica charantia, Pterocarpus marsupium, Gymnema sylvestre, Salacia reticulata, Eugenia jambolana, and a bioavailability enhancer piperine from Piper nigrum.
\end{abstract}

Objective: The antihyperglycemic potential of GlycaCare-Il was compared against metformin in a double-blind study.

Design: It was a randomized, two-arm design on prediabetic ( $N=29 ; 12$ in metformin and 17 in GlycaCare-II arm, respectively) and newly diagnosed diabetic ( $N=40 ; 16$ in metformin and 24 in GlycaCare-II) patients for 120 days.

Outcome measures: Changes in diabetic panel glycosylated hemoglobin (HbA1c), fasting blood sugar (FBS), and postprandial blood sugar (PBS) were the primary endpoints. Lipid profile, liver profile, thyroid-stimulating hormone, bilirubin and creatinine were the secondary endpoints.

Result: Twice a day treatment for 120 days with GlycaCare-ll led to a statistically significant change in $\mathrm{HbA} 1 \mathrm{c}$ $(p<0.001)$, FBS $(p<0.001)$, PBS ( $p<0.001)$ on both prediabetic and newly diagnosed diabetic patients. GlycaCare-II showed a similar potential as metformin in the treatment of T2DM. In the prediabetic group, both GlycaCare-II and metformin were comparable for all the hyperglycemic index parameters. In the case of newly diagnosed diabetic patients, GlycaCare-II showed a significantly better reduction for PBS $(p=0.026)$ as compared to metformin, while all other parameters in the diabetic panel were comparable. No adverse events were reported throughout the trial period.

Conclusion: These results suggest that GlycaCare-II is effective in managing T2DM in both newly diagnosed diabetic and prediabetic patients.

Keywords: GlycaCare-II, Metformin, Glycosylated hemoglobin, Fasting blood sugar and postprandial blood sugar, Prediabetic, Newly diagnosed diabetic and type 2 diabetes mellitus

*Correspondence: shaji@clinworld.org

1 Sami-Sabinsa Group Limited, 19/1 \& 19/2, I Main, II Phase, Peenya Industrial Area, Bangalore 560 058, Karnataka, India

Full list of author information is available at the end of the article

\section{Introduction}

Type 2 diabetes mellitus (T2DM) is a persistent hyperglycemic disorder, wherein blood glucose levels are above the normal values. Further, it is also characterized by an increase in oxidative stress $[1,2]$. T2DM is a major original author(s) and the source, provide a link to the Creative Commons licence, and indicate if changes were made. The images or other third party material in this article are included in the article's Creative Commons licence, unless indicated otherwise in a credit line to the material. If material is not included in the article's Creative Commons licence and your intended use is not permitted by statutory regulation or exceeds the permitted use, you will need to obtain permission directly from the copyright holder. To view a copy of this licence, visit http://creativecommons.org/licenses/by/4.0/. The Creative Commons Public Domain Dedication waiver (http://creativeco mmons.org/publicdomain/zero/1.0/) applies to the data made available in this article, unless otherwise stated in a credit line to the data. 
public health concern with multiple debilitating complications. Despite considerable improvement in medical sciences, diabetes mellitus is still an incurable disease rapidly increasing in all age groups [3]. The International Diabetes Federation estimated that the global diabetes prevalence in 2019 is 463 million people, rising to 578 million by 2030 and 700 million by 2045 [4]. Hyperglycemia causes both macrovascular (coronary artery disease, peripheral arterial disease, and stroke) and microvascular complications (diabetic nephropathy, neuropathy, and retinopathy) [5]. The overall glycemic burden over time as measured by glycosylated hemoglobin (Hb1Ac) determines the risk for microvascular complications [6].

T2DM is treated by numerous drugs to increase glucose metabolism and insulin secretion. Biguanide, Sulphonylureas, Alpha-glucosidase inhibitors, Thiazolidinediones, and Gliptins are the commonly prescribed medication for T2DM [7]. Most of these drugs reduce circulating glucose levels and $\mathrm{HbA1c}$ to a similar extent but differ in their safety and pathophysiological effects [8]. Metformin is accepted as the first-line therapy for T2DM. It has an extensive safety margin, decreases hepatic glucose production, and mildly affects peripheral resistance [9]. Lactic acidosis, drowsiness, muscle pain gastrointestinal problems are a few side effects associated with metformin, while some people experience B-12 deficiency [9]. Sulfonylureas help increase insulin secretion and may also increase the responsiveness of pancreatic $\beta$-cells to glucose. They are well tolerated, although hypoglycemia and weight gain are the most common side effects. Further, their long-term durability effect is inferior to metformin [10]. The PPAR- $\gamma$ agonists maintain long-term control of blood glucose levels by reducing insulin resistance and improving $\beta$-cell function. Bodyweight gain and fluid retention are the major adverse effect of this class of antidiabetic drugs [11] The glucose-dependent insulinotropic polypeptide (GIP) and GLP-1 are peptide hormones (incretins) secreted in the small intestine, which activate insulin secretion in healthy individuals. Incretin mimetics and dipeptidyl peptidase-4 (DPP-4) inhibitors have a positive effect on sustained improvement in glycemic control and on weight gain [12]. The safety of DPP-4 or GLP-1 therapy over time is not yet clear as thyroid cancer and pancreatitis have been reported [8]. Although initial response to drugs like metformin may be good, oral hypoglycemic drugs lose their effectiveness in a significant percentage of patients [13].

In recent decades, there has been a collective determination for pursuing alternative medicine for the treatment of T2DM from natural or herbal sources [14]. Other factors such as patient compliance have led the way in trying out alternative, complementary medicine. Nutritional therapy is gaining importance in preventing, managing, and slowing the rate of development of diabetes complications. It is, therefore, important at all levels of diabetes prevention [15].

Medicinal herbs from India and China have been widely used for more than 2000 years to treat type 2 diabetes mellitus [16]. The mechanism of action of the herbal medicines involves modifying glycemic metabolism, reducing cholesterol levels, and facilitating insulin secretion [17].

GlycaCare-II ${ }^{\circledR}$ is the formulation containing Cinnamomum cassia, Momordica charantia, Pterocarpus marsupium, Gymnema sylvestre, Salacia reticulata, Eugenia jambolana and piperine from Piper nigrum. The cinnamaldehyde in $C$. cassia sensitizes the body to insulin by enhancing insulin-stimulated tyrosine phosphorylation [18], while the cinnamon polyphenols display insulin-like activity [19]. M. charantia has molecules like charantin, vicine, and polypeptide-p(insulin-like hypoglycemic protein), which possess an antihyperglycemic effect with a mechanism similar to insulin [20]. Thus, some of the proposed mechanism of $M$. charantia in T2DM includes insulin-like effects and reduction in glucose absorption [21].

P. marsupium extract has been documented to help in protection against oxidative stress in diabetes [22]. Pterostilbene, present in the extract, normalizes serum insulin levels and reduces oxidative stress in diabetic rats [23]. The C-glycosides present in $P$. marsupium was found to increase glucose uptake by skeletal muscles and could be the active constituent responsible for antihyperglycemic activity [24].

Gymnemic acid from Gymnema sylvestre is a mixture of at least 23 different saponins with a similar atomic arrangement to glucose. It acts as an antihyperglycemic agent by filling the receptor location, preventing sugar molecules' absorption by the intestine [25]. Salacinol and Mangiferin from Salacia reticulata inhibit the alphaglucosidase enzyme, thus decreasing the plasma glucose level $[26,27]$.

The bark of Eugenia jambolana is rich in several bioactive compounds [28-30]. Its fruits contain raffinose which has hypoglycemic activities [31-35]. The bloodglucose-lowering effect of Eugenia jambolana may be due to increased secretion of insulin from the pancreas or by inhibition of insulin degradation [36].

Piperine enhances the absorption of nutrients through epithelial cell modification and promotes permeability [37]. Piperine, through its multifaceted effect on bioavailability has an indirect impact in the treatment of T2DM $[38,39]$.

Although various herbal products are in use for T2DM, only a few products have been compared with metformin, and even in the comparison, the outcome of 
antihyperglycemic activity was lower than that of metformin [40]. Hence, the purpose of this study was to evaluate and compare the efficacy and safety of GlycaCare-II against metformin for the management of T2DM in prediabetic and newly diagnosed patients.

\section{Materials and methods Test product}

GlycaCare-II ${ }^{\circledR}$ tablets $(522.5 \mathrm{mg})$ was manufactured and provided by Sami-Sabinsa Group Limited (erstwhile Sami Labs Limited), India. GlycaCare-II ${ }^{\circledR}$ contains the following ingredients:

\begin{tabular}{|c|c|c|c|}
\hline SI.no & Ingredients & Qty/mg & $\begin{array}{l}\text { Percentage (\%) } \\
\text { of Actives }\end{array}$ \\
\hline 1 & Cinnamon Extract & 150 & $20 \%$ polyphenols \\
\hline 2 & $\begin{array}{l}\text { Momordica charantia } \\
\text { Extract }\end{array}$ & 150 & $0.5 \%$ Charantin \\
\hline 3 & $\begin{array}{l}\text { Pterocarpus Extract } \\
\text { (Water-soluble) }\end{array}$ & 150 & $5 \%$ C-glycosides \\
\hline 4 & Gymnema sylvestre Extract & 30 & $25 \%$ gymnemic acids \\
\hline 5 & Salacia reticulata extract & 20 & 1\% Mangiferin \\
\hline 6 & $\begin{array}{l}\text { Eugenia jambolana } \\
\text { extract }\end{array}$ & 20 & $<15 \%$ Tannins \\
\hline 7 & Piperine(Bioperine) & 2.5 & 95\% Piperine \\
\hline
\end{tabular}

Cinnamon (Cinnamomum cassia) bark, Gymnema (Gymnema sylvestre) leaves, deseeded (Momordica charantia) fruits, Dried fruits of Jamun(Eugenia jambolana), and Dried Salacia bark (Salacia reticulata) were powdered and extracted with methanolic water at refluxed condition. The extract was concentrated to remove methanol, dissolved in water, and spray dried. Dried Pterocarpus wood (Pterocarpus marsupium) was extracted with water.

Metformin (GLYCIRITE) tablets $(500 \mathrm{mg}$ ) was manufactured by Tusker Pharma India Pvt. Ltd, India.

\section{Study design}

The present study was a prospective, randomized, double-blind, active-controlled clinical trial. Its primary objective was to evaluate the efficacy and safety of GlycaCare-II as monotherapy in Type 2 diabetes mellitus patients compared to metformin. Enrolled patients were initially segregated into prediabetic patients and newly diagnosed diabetic patients. The patients were randomly allocated into two treatment groups to prevent treatment bias. The patients and investigators were blinded to the treatment allocation. Out of 70 subjects screened, sixty-nine subjects enrolled in the study. All the enrolled patients were randomized to two treatment groups: Treatment 1: GlycaCare-II $(522.5 \mathrm{mg})$ as active or Treatment 2: Metformin (500 mg) as the comparator. During the treatment phase, 29 prediabetic patients and 40 newly diagnosed diabetic patients with Type 2 Diabetes mellitus were randomized to receive either GlycaCare-II or metformin under each arm for a period of 120 days \pm 3 days. Investigational Product (IP) was administered orally twice daily, morning and night, 20 min before food. All the participants signed informed consent before the beginning of the study after careful detailing regarding the purpose, procedure, and potential risks and benefits of the study.

\section{Study population}

Subjects within the age group of 30-65 years, having the ability to comply with the study protocol and willing to give written consent, were included in the study. Prediabetes was classified as per American diabetes association criteria HbA1c 5.7-6.4\% and FBS between $100 \mathrm{mg} /$ dL to $125 \mathrm{mg} / \mathrm{dL}$. Newly diagnosed diabetes patients had an $\mathrm{HbA} 1 \mathrm{c}$ value of $6.5-7.5 \%$ and $\mathrm{FBS}>125 \mathrm{mg} / \mathrm{dL}$ [41]. Pregnant and lactating women, patients with a history of acute or chronic illness, type I diabetes, hypo-, and hyperthyroidism were excluded from the study. Also, subjects with hyperlipidemia, history of severe hepatic dysfunction or renal dysfunction, uncontrolled pulmonary dysfunction, and poorly controlled hypertension were excluded from the study. Any patient did not use concomitant medications during the course of the trial.

Details of the subject's disposition are presented in the consort flow chart (Fig. 1).

\section{Ethics and informed consent}

The study was planned at two centers; however, executed at only one site, Levin Diabetes Specialty Hospital, Madurai. The institutional ethics committee of both the hospitals approved it. However, the trial activity was terminated at the initial phase of the study at Pristine Hospital \& Research Centre (P) Ltd due to non-compliance. The study was conducted on 69 subjects instead of the proposed 140 subjects. A protocol deviation pertaining to the change in the number of subjects was filed to the ethics committee, and the changes were duly updated in the Clinical Trial Registry of India (CTRI) with registration number CTRI/2018/02/012085 on February 22, 2018, retrospectively. Written Informed Consent was taken from all the subjects before enrolling in the study.

\section{Data collection, compliance, and protocol deviation}

This study was conducted in accordance with applicable regulations, GCP, and Standard Operating Procedures. Study monitor(s) from ClinWorld monitored the study process and data collection through periodical site visits. The monitor retrieved the CRFs (Case Report Form) upon satisfactory resolution of all the queries. 


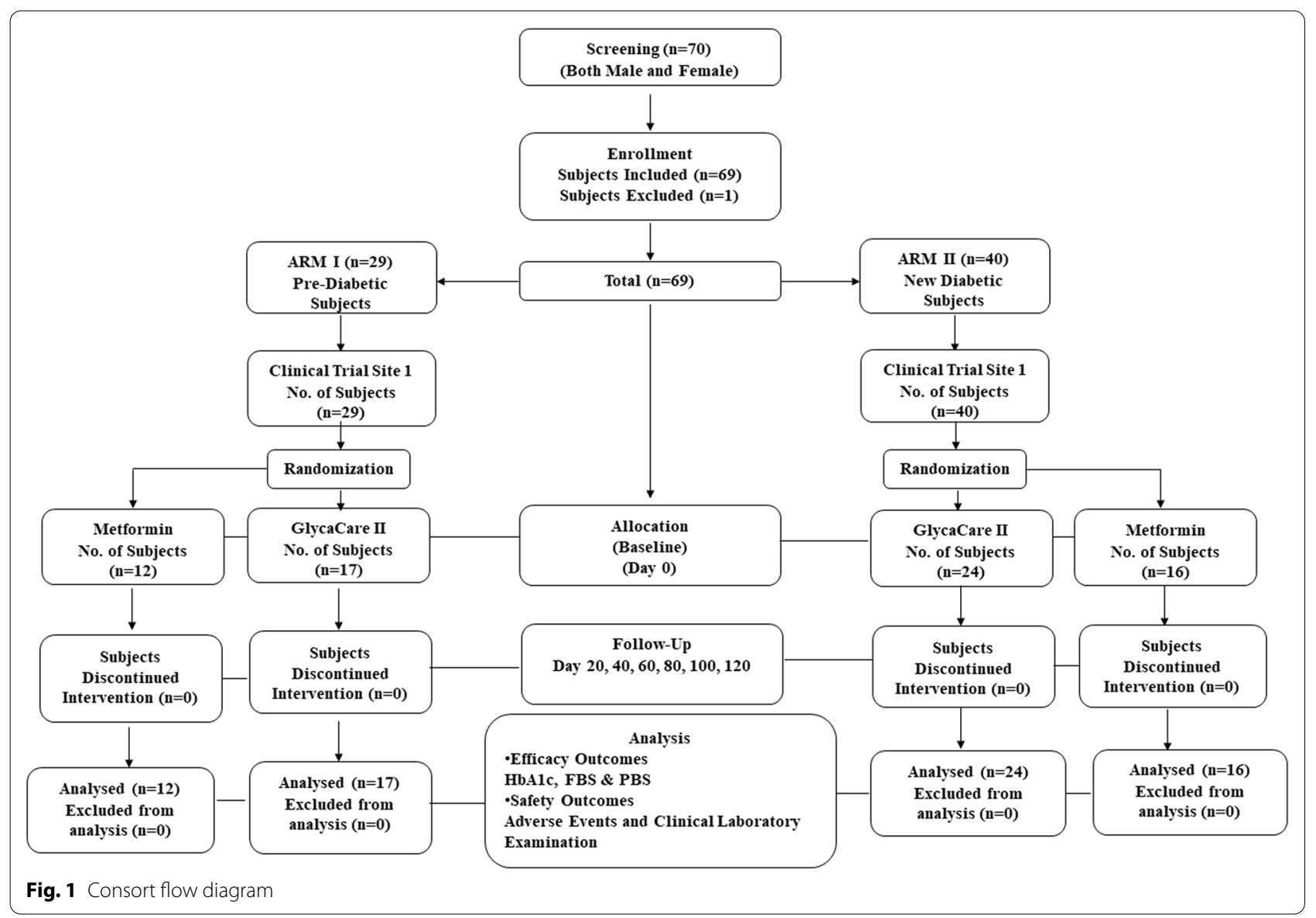

Investigational Product (IP) compliance was maintained for both active tablets GlycaCare-II and comparator Glycirite tablets. IP compliances were assessed through CRF. There were no deviations observed regarding IP compliance, during the treatment.

\section{Study outcome}

Change in diabetic panel (Glycosylated hemoglobin (HbA1c), fasting blood sugar (FBS), and postprandial blood sugar (PBS)) is the primary endpoint. In case of secondary endpoints, adverse events and change in the biochemical parameters viz lipid profile (Total cholesterol (TC), triglycerides (TG), low-density lipoprotein (LDL), high-density lipoprotein (HDL), very low-density lipoprotein (VLDL)), liver profile (aspartate transaminase (AST), alanine transaminase (ALT)) and renal profile (Serum creatinine) were performed. All routine clinical chemistry parameters were analyzed using Erba Chem $5^{\circledR}$ Plus V2 (ERBA Diagnostics Mannheim GmbH Mallaustrasse 69-73 68,219 Mannheim, Germany). Hematology was analyzed using 6 part cell analyzer, SYSMEX, XN-150, (Mumbai, 400 078, Maharashtra, India). HbA1c was analyzed using a D-10 analyzer, BIO-RAD Laboratories (Hercules, CA, USA).

Efficacy and safety parameters were assessed during the patients' visits to the site. Physical examination, demographics (height, weight, body mass index (BMI)), vital signs were assessed at each visit of the subjects. Clinical efficacy parameter HbA1c was assessed at the screening visit (day - 3) and final visit (day $120 \pm 3$ ). FBS and PBS were assessed at the screening visit (day -3 ), visit 3 (day $20 \pm 3$ ), visit 4 (day $40 \pm 3$ ), visit 5 (day $60 \pm 3$ ), visit 6 (day $80 \pm 3$ ), visit 7 (day $100 \pm 3$ ) and final visit (day 120士3). All the biochemical parameters viz thyroid profile (thyroid-stimulating hormone-TSH), lipid profile, liver profile, and renal profile were assessed at the screening visit

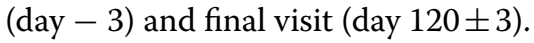

\section{Statistical analysis}

All patients in the study with relevant safety and efficacy data were considered for the analysis. Efficacy and safety endpoints were analyzed for the relevant study population. A descriptive analysis of demographic characteristics was performed. Mean, and the standard 
deviation was derived for numeric and categorical parameters. Vital signs at each visit were also analyzed descriptively. Both primary and secondary efficacy outcomes were analyzed descriptively.

For normally distributed data, parametric tests have been applied, and results on continuous measurements were presented as mean $\pm S D$, and results on categorical measurements were presented in percentage (\%). A statistical significance level of $\leq 5 \%$ was considered significant. Fasting and postprandial glucose levels have been evaluated using repeated-measures ANOVA. HbA1c levels at the screening visit (visit 1 ) and at the end of the treatment were evaluated using student's - paired t-test.

As part of safety outcomes, adverse events, concomitant medications, and clinical laboratory data were assessed. Clinical laboratory outcomes were assessed descriptively. Mean and standard deviation were derived from the data. The p-value for each efficacy parameter and for individual laboratory parameters was calculated using the Wilcoxon test.

\section{Results}

\section{Demographics and other baseline characteristics}

A total number of 69 subjects were enrolled and completed the study with an average age range of 48-52.9 years. The demographic parameters were comparable between the metformin and GlycaCare-II treatments at baseline. The other demographic parameters are as shown in Table 1.

\section{Efficacy analysis of GlycaCare-II and metformin Newly diagnosed diabetic patients}

Effect on HbA1c level One of the primary efficacy parameters recorded for this clinical study was a change in the level of $\mathrm{HbA} 1 \mathrm{c}$ from screening visit to final visit. In the case of newly diagnosed diabetic patients, the HbA1c level was $6.99 \pm 0.32 \%$ for GlycaCare-II and $6.99 \pm 0.38 \%$ for the metformin group at the screening visit. In the final visit, the HbA1c level reduced to $6.52 \pm 0.19 \%$ $(\mathrm{p}<0.001)$ for GlycaCare-II and $6.53 \pm 0.26 \%(\mathrm{p}=0.004)$ for metformin. The mean changes in $\mathrm{HbA} 1 \mathrm{c}$ were not significantly different in metformin \& GlycaCare-II groups, suggesting equivalent efficacy (Fig. 3A).

Effect on fasting blood sugar FBS level recorded a reduction of $11 \%$ for GlycaCare-II, and a similar improvement in the FBS level was observed in the metformin arm with a $10 \%$ reduction at visit 8 (Fig. 3B).
Effect on postprandial blood sugar A significant change in the PBS level at the final visit as compared to the screening visit was observed in both GlycaCare-II $(\mathrm{p}<0.0001)$ and metformin $(\mathrm{p}=0.0005)$ groups in the newly diagnosed diabetes patients. Total change in the PBS level was significant between the treatment groups $(\mathrm{p}=0.0268)$. In the case of PBS level, GlycaCare-II displayed a significant therapeutic response compared to metformin with the absolute mean change of $32.75 \mathrm{mg} /$ $\mathrm{dl}$ as against $21.06 \mathrm{mg} / \mathrm{dL}$ of metformin group. Additionally, a significant change was observed in the PBS value from visit three onwards within the group for GlycaCare-II and metformin. Further, these changes were incremental across the time points for both groups (Fig. 3C).

\section{Prediabetic patients}

Effect on HbA1c level The mean HbA1c changed from $6.16 \pm 0.21$ to $5.87 \pm 0.15 \%(\mathrm{p}<0.001)$ in GlycaCare-II group and $6.2 \pm 0.24$ to $5.97 \pm 0.21 \%(\mathrm{p}=0.02)$ in metformin group, from screening visit to final visit. The mean changes in $\mathrm{HbA1c}$ were not significantly different in metformin \& GlycaCare-II groups, suggesting equivalent efficacy (Fig. 4A).

Effect on fasting blood sugar A significant change was observed in the FBS level from Day 20 onwards for both GlycaCare-II and metformin group, and the changes were incremental across the time points with resultant $15 \%$ and $11 \%$ reduction at 120 days, respectively in the pre-diabetics group (Fig. 4B).

Effect on postprandial blood sugar In the prediabetes patients, the PBS level visit-wise for both GlycaCareII and metformin showed steady augmentation over a period. The PBS level for GlycaCare-II at the screening visit was $169.59 \pm 16.35 \mathrm{mg} / \mathrm{dl}$ and for the final visit $146 \pm 8.66 \mathrm{mg} / \mathrm{dl} \quad(\mathrm{p}<0.0001)$. For metformin it was $165.67 \pm 14.89 \mathrm{mg} / \mathrm{dl}$ at screening visit (day 3) and $148 \pm 8.31 \mathrm{mg} / \mathrm{dl}$ for final visit (day-120 \pm 3 ) $(p=0.0016)$. Additionally, a significant change within the group was observed in the PBS level from visit five onwards for GlycaCare-II, and the changes were incremental across the time points. However, a significant change was observed for the metformin group from visit 6 , with the incremental difference across the time points (Fig. 4C). 


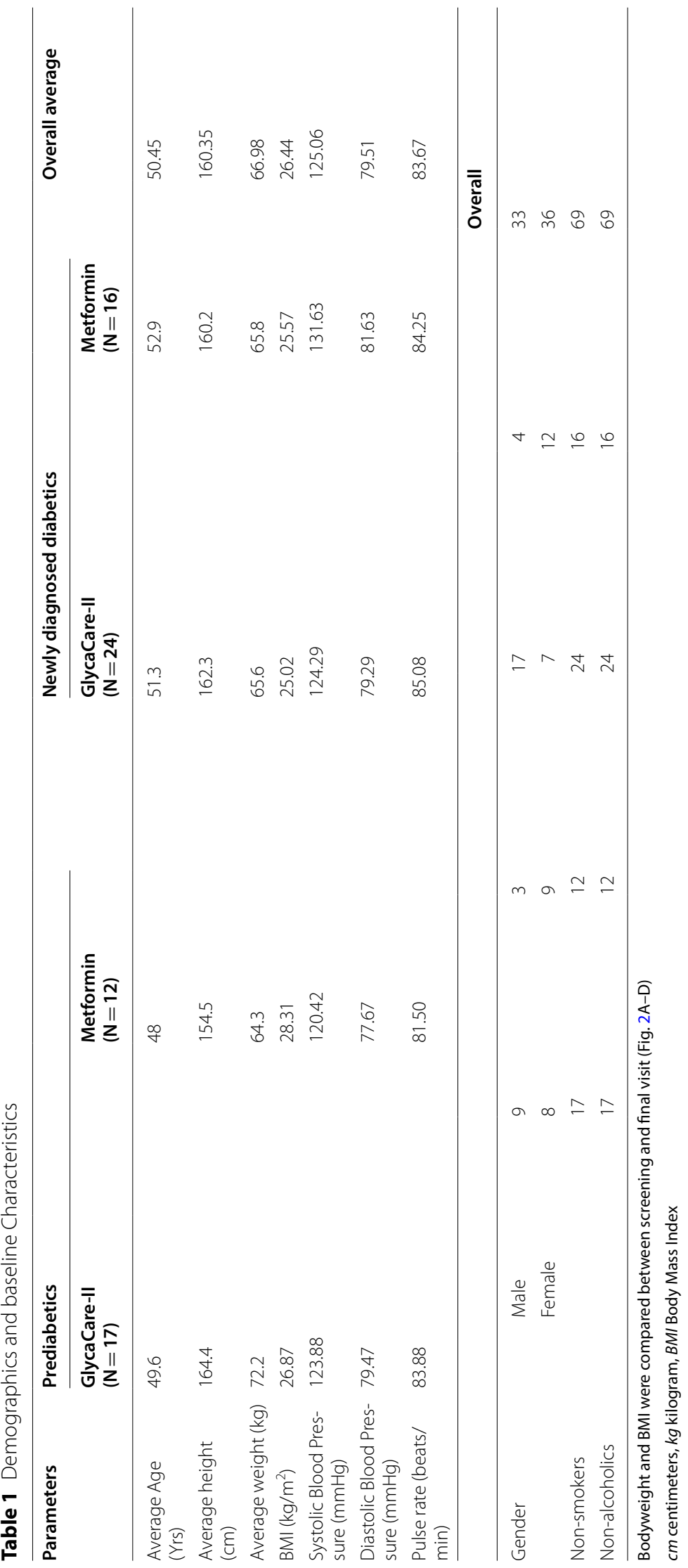



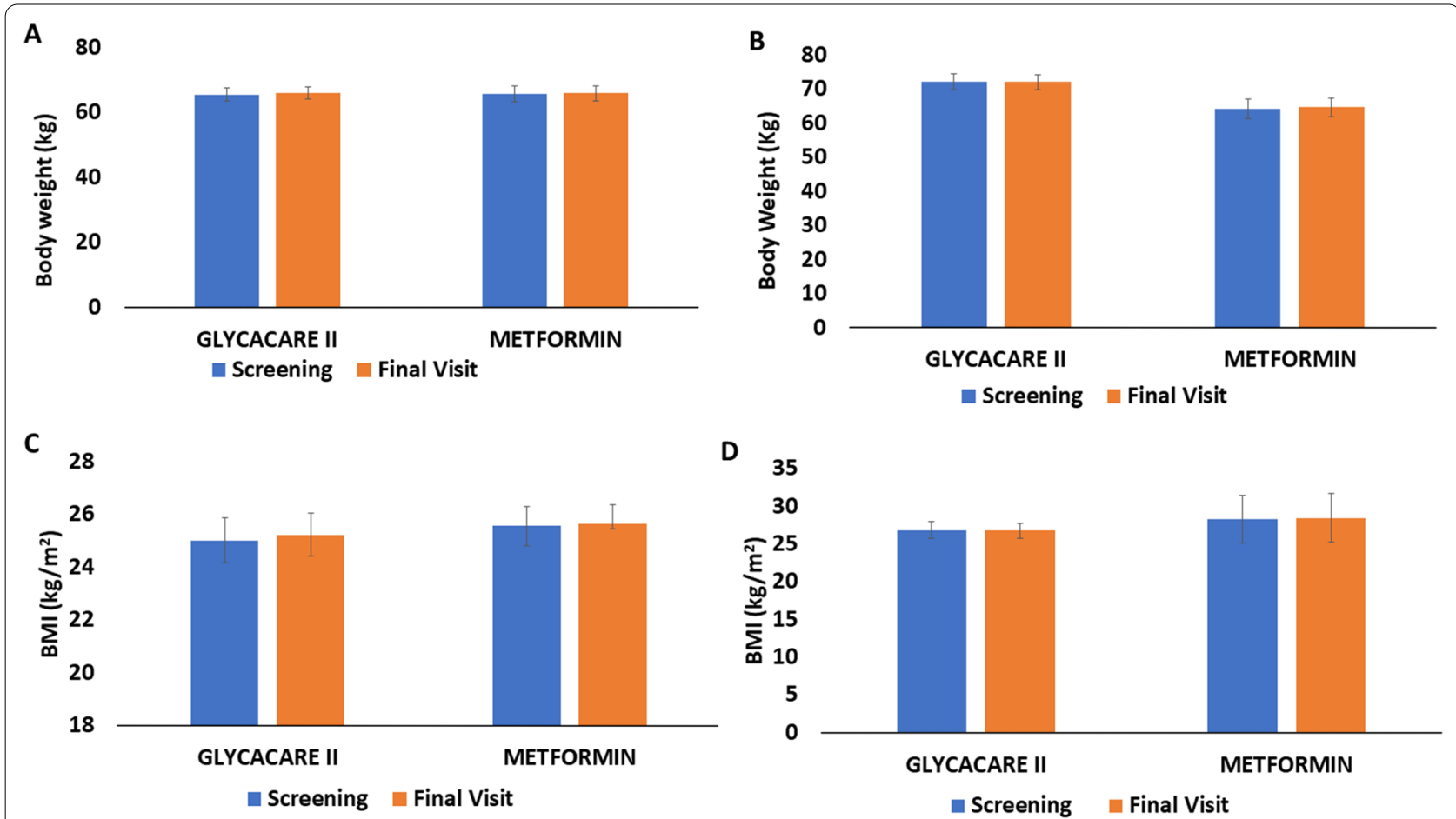

Fig. 2 Bodyweight and BMI comparison from screening to final visit. A Body weight change in newly diagnosed diabetic group B Bodyweight change in prediabetic group C BMl change in newly diagnosed diabetic group D BMl change in prediabetic group; Values are expressed as Mean \pm SE

\section{Safety evaluation}

There were no adverse events or serious adverse events observed, and none of the patients consumed any concomitant medications during the study in both prediabetic and newly diagnosed diabetic arms.

\section{Clinical laboratory evaluation \\ Lipid levels}

The reduction in TC, TG, LDL, VLDL, and the increase in HDL was highly significant in the GlycaCare-II treated subjects. Metformin did not show a significant reduction in TG and VLDL. The positive effect on lowering lipids was better with GlycaCare-II compared to metformin. This effect was not observed in prediabetic subjects (Table 2).

\section{Safety parameters}

\section{Newly diagnosed diabetic arm}

Bilirubin, and creatinine, changed significantly in metformin group in comparison to baseline. It was also noted that the total bilirubin increased significantly in the patients treated with metformin at the end of the study in comparison to the GlycaCare-II group. The vital parameters did not show any significant changes across the study period in both arms. Nevertheless, the respiratory rate of the metformin group was significantly decreased at the end of the study. These results reiterate the safety of GlycaCare-II for human consumption in newly diagnosed diabetic patients (Table 3).

\section{Prediabetic arm}

Clinical laboratory evaluation was carried out on the study participants during screening and final visit. The biochemical parameters during the screening and the final visit, showed no significant change across time. The vital parameters did not show any significant changes across the study period in both the arms. These results reiterate the safety of GlycaCare II and metformin for human consumption in prediabetic patients (Table 3 ).

\section{Discussion}

In the present study, we observed that a herbal formulation (GlycaCare-II), containing natural extracts of Cinnamomum cassia, Momordica charantia, Pterocarpus marsupium, Gymnema sylvestre, Salacia reticulata, Eugenia jambolana with a small quantity of piperine as bioavailability enhancer was comparable to metformin in 


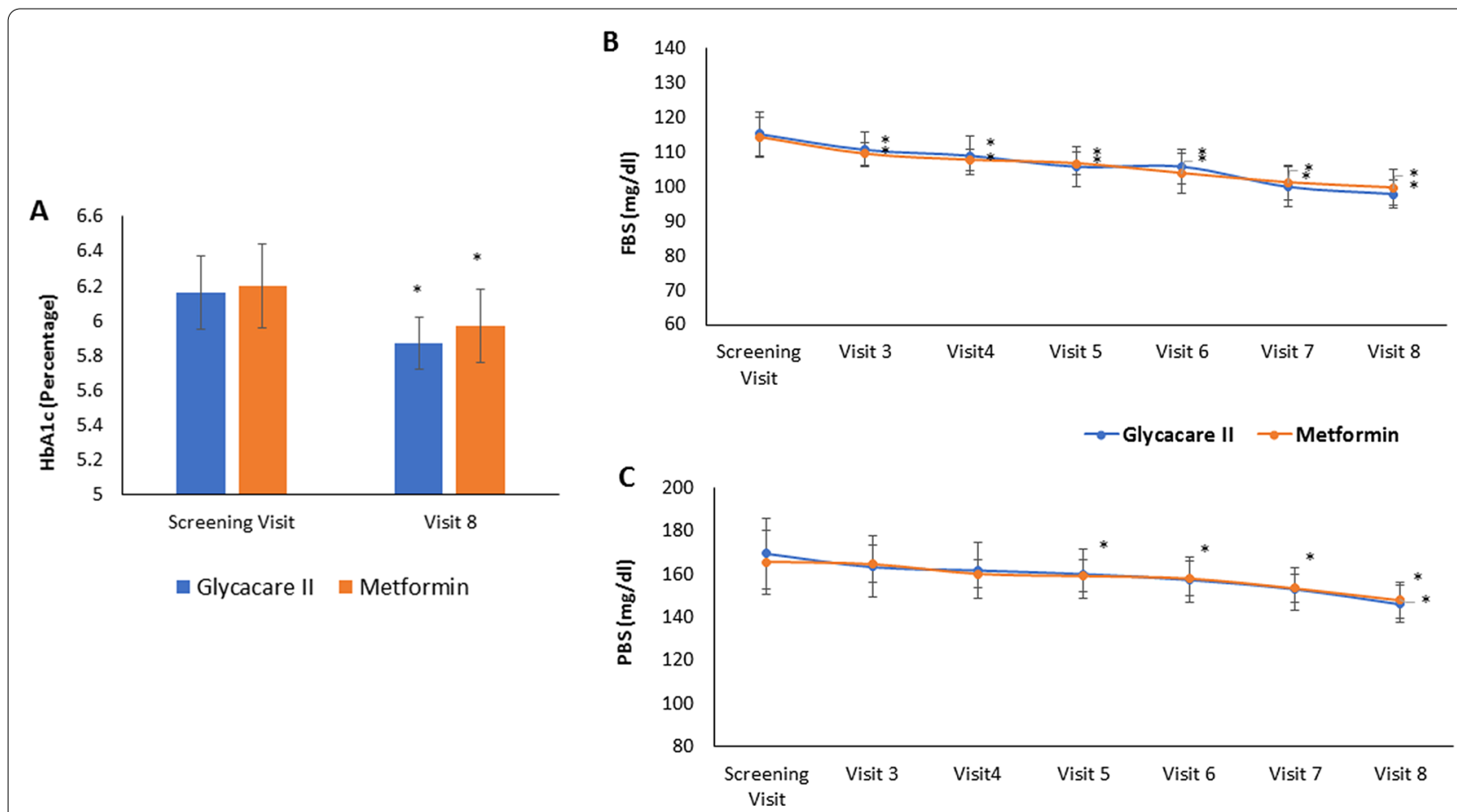

Fig. 3 Efficacy parameter for GlycaCare-II and Metformin in newly diagnosed diabetic patients, FBS and PBS was measured at the screening visit (visit 1), visit 3, visit 4, visit 5, visit 6, visit 7 and visit 8and $\mathrm{HbA1C}$ was measured at screening and final visit (visit 8). A HbA1c level in \%, B Fasting blood sugar level in $\mathrm{mg} / \mathrm{dL}, \mathbf{C}$ Postprandial blood sugar level in $\mathrm{mg} / \mathrm{dL}$. (Values are expressed as Mean $\pm \mathrm{SD},{ }^{*} p<0.05$ in comparison to screening visit by repeated measure ANOVA)

A

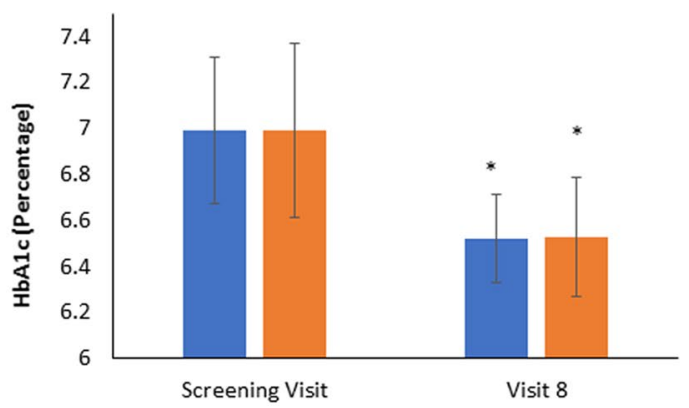

Glycacare II Metformin
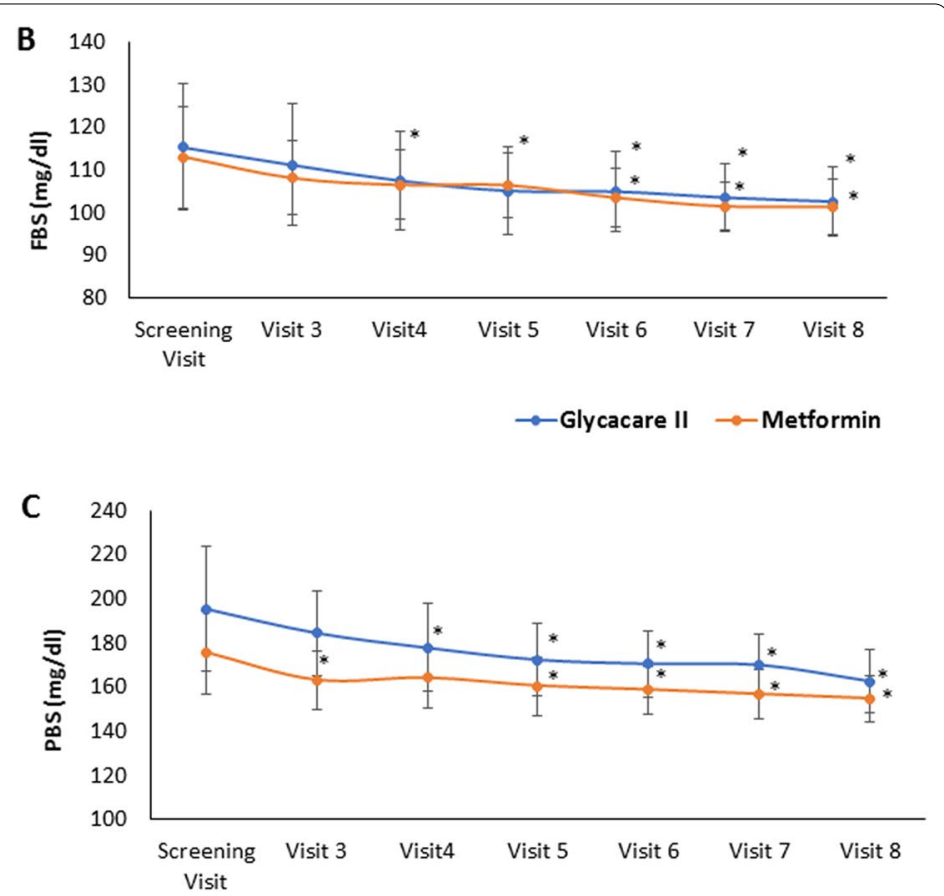

Fig. 4 Efficacy parameter for GlycaCare-Il and metformin in prediabetics arm, FBS and PBS was measured at the screening visit (visit 1), visit 3, visit 4, visit 5, visit 6, visit 7 and visit 8, HbA1c was measured at screening and final visit (visit 8). A HbA1c level in \%, B Fasting blood sugar level in mg/ $\mathrm{dL}, \mathbf{C}$ Postprandial blood sugar level in $\mathrm{mg} / \mathrm{dL}$. (Values are expressed as Mean $\pm \mathrm{SD},{ }^{*} \mathrm{p}<0.05$ in comparison to screening visit by repeated measure ANOVA) 
Table 2 Lipid profile for GlycaCare-II and Metformin

\begin{tabular}{|c|c|c|c|c|c|c|c|}
\hline \multirow{2}{*}{$\begin{array}{l}\text { Group } \\
\text { Day }\end{array}$} & \multirow[t]{3}{*}{ Product } & \multicolumn{3}{|l|}{ Prediabetic } & \multicolumn{3}{|c|}{ Newly diagnosed diabetic } \\
\hline & & 0 & 120 & P-value & 0 & 120 & P-value \\
\hline Parameter & & Mean \pm SD & Mean \pm SD & & Mean \pm SD & Mean \pm SD & \\
\hline \multirow[t]{2}{*}{$\mathrm{TC}(\mathrm{mg} / \mathrm{dl})$} & GlycaCare-II & $194.29 \pm 22.26$ & $180.88 \pm 20.35$ & 0.0761 & $208.96 \pm 25.18$ & $187.04 \pm 16.27$ & $0.0008 \downarrow^{*}$ \\
\hline & Metformin & $184.17 \pm 14.78$ & $179.00 \pm 15.71$ & 0.4153 & $198.31 \pm 12.84$ & $185.69 \pm 15.10$ & $0.0162 \downarrow^{*}$ \\
\hline \multirow[t]{2}{*}{$\mathrm{TG}(\mathrm{mg} / \mathrm{dl})$} & GlycaCare-II & $162.00 \pm 21.98$ & $157.00 \pm 18.88$ & 0.4819 & $172.13 \pm 18.44$ & $157.13 \pm 14.61$ & $0.0031 \downarrow^{*}$ \\
\hline & Metformin & $151.50 \pm 28.79$ & $152.42 \pm 13.60$ & 0.9212 & $162.88 \pm 14.87$ & $158.31 \pm 18.82$ & 0.4519 \\
\hline \multirow[t]{2}{*}{$\mathrm{HDL}(\mathrm{mg} / \mathrm{dl})$} & GlycaCare-II & $38.82 \pm 4.45$ & $36.29 \pm 3.84$ & 0.0855 & $41.75 \pm 4.87$ & $37.46 \pm 3.30$ & $0.0008 \downarrow^{*}$ \\
\hline & Metformin & $39.42 \pm 6.84$ & $35.17 \pm 2.37$ & $0.0542 \downarrow$ & $40.00 \pm 3.14$ & $37.257 \pm 3.47$ & $0.0255 \downarrow^{*}$ \\
\hline \multirow[t]{2}{*}{$\mathrm{LDL}(\mathrm{mg} / \mathrm{dl})$} & GlycaCare-II & $120.41 \pm 19.92$ & $113.35 \pm 13.29$ & 0.2330 & $132.21 \pm 17.81$ & $118.13 \pm 11.10$ & $0.0019 \downarrow^{*}$ \\
\hline & Metformin & $115.33 \pm 10.06$ & $110.92 \pm 14.19$ & 0.3893 & $125.88 \pm 13.88$ & $114.19 \pm 12.29$ & $0.0172 \downarrow^{*}$ \\
\hline \multirow[t]{2}{*}{ VLDL (mg/dl) } & GlycaCare-II & $32.47 \pm 4.56$ & $31.24 \pm 3.73$ & 0.3957 & $34.58 \pm 3.69$ & $31.46 \pm 2.81$ & $0.0019 \downarrow^{*}$ \\
\hline & Metformin & $30.42 \pm 5.87$ & $30.17 \pm 3.97$ & 0.9038 & $32.99 \pm 3.06$ & $31.63 \pm 3.91$ & 0.2819 \\
\hline
\end{tabular}

SD Standard deviation, $T C$ total cholesterol, TG TriGlycerides, $H D L$ high-density lipoproteins, $L D L$ low-density lipoproteins, VLDL very low-density lipoproteins, $\uparrow^{*}=$ Statistically significant increase $(p<0.05), \downarrow^{*}=$ Statistically significant decrease $(p<0.05)$, No. of Subjects (Prediabetics: GlycaCare-II-17 \& Metformin-12, Newly diagnosed diabetic: GlycaCare-II-24 \& Metformin-16)

Table 3 Safety profile of GlycaCare-II and Metformin

\begin{tabular}{|c|c|c|c|c|c|c|c|}
\hline \multirow{2}{*}{$\begin{array}{l}\text { Group } \\
\text { Day }\end{array}$} & \multirow[t]{3}{*}{ Product } & \multicolumn{3}{|l|}{ Prediabetic } & \multicolumn{3}{|c|}{ Newly diagnosed diabetic } \\
\hline & & 0 & 120 & P-value & 0 & 120 & P-value \\
\hline Parameter & & Mean \pm SD & Mean \pm SD & & Mean \pm SD & Mean \pm SD & \\
\hline \multirow[t]{2}{*}{ TSH $(\mu \mathrm{lU} / \mathrm{ml})$} & GlycaCare-II & $2.72 \pm 0.59$ & $2.55 \pm 0.60$ & 0.4110 & $3.08 \pm 0.65$ & $3.01 \pm 0.66$ & 0.7129 \\
\hline & Metformin & $2.39 \pm 0.94$ & $2.70 \pm 0.98$ & 0.4375 & $3.04 \pm 0.71$ & $2.94 \pm 0.71$ & 0.6932 \\
\hline \multirow[t]{2}{*}{ Total bilirubin (mg/dl) } & GlycaCare-II & $0.86 \pm 0.14$ & $0.85 \pm 0.14$ & 0.8364 & $0.89 \pm 0.14$ & $0.86 \pm 0.12$ & 0.4295 \\
\hline & Metformin & $0.82 \pm 0.13$ & $0.78 \pm 0.13$ & 0.4590 & $0.71 \pm 0.13$ & $0.80 \pm 0.06$ & $0.0175 \uparrow^{*}$ \\
\hline \multirow[t]{2}{*}{ AST (IU/L) } & GlycaCare-II & $27.47 \pm 7.79$ & $28.00 \pm 6.48$ & 0.8306 & $28.21 \pm 7.05$ & $28.00 \pm 6.85$ & 0.9171 \\
\hline & Metformin & $24.58 \pm 7.32$ & $25.17 \pm 5.91$ & 0.8300 & $21.94 \pm 8.34$ & $22.94 \pm 5.64$ & 0.6940 \\
\hline \multirow[t]{2}{*}{$\operatorname{ALT}(I U / L)$} & GlycaCare-II & $24.41 \pm 3.69$ & $22.94 \pm 3.68$ & 0.2534 & $26.83 \pm 4.68$ & $26.17 \pm 6.18$ & 0.6786 \\
\hline & Metformin & $25.00 \pm 4.02$ & $26.25 \pm 3.39$ & 0.4191 & $25.19 \pm 5.65$ & $25.63 \pm 5.06$ & 0.8181 \\
\hline \multirow[t]{2}{*}{ Total creatinine (mg/dl) } & GlycaCare-II & $0.86 \pm 0.11$ & $0.85 \pm 0.11$ & 0.7927 & $0.88 \pm 0.13$ & $0.87 \pm 0.13$ & 0.7911 \\
\hline & Metformin & $0.91 \pm 0.10$ & $0.88 \pm 0.21$ & 0.6845 & $0.80 \pm 0.21$ & $1.07 \pm 0.29$ & $0.0052 \uparrow *$ \\
\hline
\end{tabular}

SD Standard deviation, TSH Thyroid Stimulating Hormone, AST Aspartate Aminotransferase, ALT Alanine Transaminase, $\uparrow^{*}=$ Statistically significant increase ( $\left.<<0.05\right)$, $\downarrow^{*}=$ Statistically significant decrease $(p<0.05)$, No. of Subjects (Prediabetics: GlycaCare-II-17 \& Metformin-12, Newly diagnosed diabetic: GlycaCare-II-24 \& Metformin-16)

reducing hyperglycemia and HbA1c levels on both prediabetic and newly diagnosed diabetic patients.

Compared with the baseline data, significant improvement in all the primary biochemical indices of hyperglycemia like HbA1c, FBS, and PBS was observed in all the subgroups after four months of treatment. The GlycaCare-II formulation was safe with no changes in blood biochemical parameters, and no adverse effects were reported during the four months of treatment. In subjects treated with metformin, a significant increase in creatinine and bilirubin levels was observed in newly diagnosed diabetic patients. Although the number of subjects was low, this trend cannot be ignored and warrants a larger cohort study. Few earlier studies on chronic therapy of metformin reported a significant change in creatinine [42, 43].

GlycaCare-II exhibited a significant change in PBS level compared to metformin at the end of the study, especially in the newly diagnosed diabetic patients. Further, GlycaCare-II showed statistically significant improvement in lipid levels suggesting its benefit in controlling dyslipidemia. These inferences are in line with other studies, wherein individual components of this formulation were efficacious in bringing down 
metabolic index $[18,21,40,44-46]$. The treatment of GlycaCare-II was devoid of any adverse events, and the outcome of the analysis of the laboratory parameters suggests that GlycaCare-II is safe for diabetic patients.

Optimal treatment of type 2 diabetes mellitus requires a comprehensive and concerted approach. The management of the condition focuses on nutrition, exercise, and pharmacologic therapies to reduce the complications associated with hyperglycemia. In prediabetic and new-onset diabetes patients, nutrition therapy is of utmost importance to prevent further deterioration of the condition [47]. The American diabetic association recommends HbAlc with a cutpoint $\geq 6.5 \%$ for diagnosing diabetes as an alternative to fasting plasma glucose as it provides a reliable measure of chronic glycemia and correlates well with the risk of long-term diabetes complications [48]. Further, HbA1c is also a good predictor of lipid profile, providing additional benefits of identifying cardiovascular risk among diabetes patients [49]. GlycaCare-II was comparable to metformin therapy in reducing the HbAlc levels in both prediabetic and newly diagnosed diabetic patients. In addition, GlycaCare-II was highly effective in reducing lipid levels in newly diagnosed diabetic patients, which was better than the effect of metformin. These results suggest that GlycaCare-II can be a beneficial supplement for diabetic patients with dyslipidemia, which requires further elaboration. Although the lipid levels decreased in prediabetic patients also, it was not significant, probably because of the overall lower levels in these groups.

Postprandial hyperglycemia is also one of the earliest abnormalities of glucose homeostasis, and it has been suggested that lowering PPS may decrease the risk of hypoglycemia and weight gain [50]. GlycaCare-II was significantly better than metformin in reducing PPS in newly diagnosed patients, and the effect was seen at an earlier time point in prediabetic patients. These observations also suggest that GlycaCare-II may be used to successfully reduce the risk of developing diabetes in prediabetics and reduce progression in diabetic patients.

One limitation of the study was the inability to carry out the multicenter trial as per the original protocol due to non-compliance and subsequent termination of the site, resulting in smaller subgroups. We restricted the outcome parameters to only the glycemic profile as this was the first clinical study with GlycaCare-II. This can be considered a study limitation, as evaluation of insulin levels and oxidative parameters would have extended the benefits afforded by the herbal formulation.

\section{Conclusion}

The findings in this randomized clinical study demonstrate the potential of GlycaCare-II as an alternative safe medication in the treatment of T2DM. It was also evident that GlycaCare-II possesses a similar therapeutic response as compared to metformin. Future studies in a larger cohort may help in positioning the polyherbal formulation as an alternative to the standard treatment for type 2 diabetes. We have shown that GlycaCare-II, with its steady influence on reducing the hyperglycemic index, is comparable with metformin. GlycaCare-II also appeared to have a better effect on the changes in the lipid parameters. However, the intrinsic cumulative mechanisms of its action must be further established through a comprehensive trial involving an increase in the number of subjects.

\section{Abbreviations}

AST: Aspartate transaminase; ALT: Alanine transaminase; BMI: Body Mass Index; CTRI: Clinical Trial Registry of India; FBS: Fasting blood sugar; FDA: Food and Drug Administration; HbA1C: Glycosylated hemoglobin; HDL: High-density lipoprotein; IP: Investigational Product; LDL: Low density lipoprotein; PBS: Postprandial blood sugar; T2DM: Type 2 diabetes mellitus; TC: Total cholesterol; TG: Triglycerides; TSH: Thyroid Stimulating Hormone; VLDL: Very low-density lipoprotein.

\section{Acknowledgements}

We would like to thank the Clinical Trial Investigator of the study, Dr. Ravikumar Sethuraman and Levin Speciality Hospital.

\section{Authors' contributions}

Conceptualization, MM, AM, and KN; Methodology, SP; Validation, SP, and LM; Investigation, SP; Resources, MM and AM; Data Curation, SP; WritingOriginal Draft Preparation, SP; Writing-Review \& Editing, MM, AM, KN, and LM; Supervision, MM; Project Administration, AM; Funding Acquisition, MM.

\section{Funding}

This work was sponsored by Sami-Sabinsa Group Limited/Sabinsa Corporation. There was no external funding involved.

Availability of data and materials

All the data generated are within the manuscript.

\section{Declarations}

Ethics approval and consent to participate

The trial was approved by Institutional Ethics Committee, Levin Speciality Hospital Madurai before the conduct of the study. Written informed consent form was taken from all the subjects before enrolling in the study.

\section{Consent for publication}

Not applicable.

\section{Competing interests}

Dr. Muhammed Majeed is the Founder and Managing Director of SamiSabinsa Group Limited and Sabinsa Corporation. The authors declare that this study received funding from Sami-Sabinsa Group Limited/ Sabinsa Corporation. The funder was involved in conceptualizing the project and providing resources. The funder was not involved in study design, data collection, and analysis of results, but was part of reviewing the manuscript and decision to publish. All the authors are affiliated with Sami-Sabinsa Group Limited or Sabinsa Corporation. 


\section{Author details}

'Sami-Sabinsa Group Limited, 19/1 \& 19/2, I Main, II Phase, Peenya Industrial Area, Bangalore 560 058, Karnataka, India. ${ }^{2}$ Sabinsa Corporation, 20 Lake Drive, East Windsor, NJ 08520, USA.

Received: 22 July 2021 Accepted: 25 October 2021 Published online: 17 November 2021

\section{References}

1. American Diabetes Association. Standards of medical care in diabetes-2014. Diabetes Care. 2014;37:S14.

2. Bin Abas R, Das S, Thent ZC. Herbal supplements for type 2 diabetes mellitus: a systematic review of clinical results. J Exp Appl Anim Sci. 2015;1(3):341-54

3. Meo SA. Diabetes mellitus: health and wealth threat. Int J Diabetes Mellit. 2009;1(1):42

4. Saeedi P, Petersohn I, Salpea P, Malanda B, Karuranga S, Unwin N, et al. Global and regional diabetes prevalence estimates for 2019 and projections for 2030 and 2045: results from the International Diabetes Federation Diabetes Atlas. Diabetes Res Clin Pract. 2019;157:107843.

5. Fowler MJ. Microvascular and macrovascular complications of diabetes. Clin Diabetes. 2008:26(2):77-82.

6. Samanta S. Glycated hemoglobin and subsequent risk of microvascular and macrovascular complications. Indian J Med Sci. 2020;73:230-8.

7. Harrigan RA, Nathan MS, Beattie P. Oral agents for the treatment of type 2 diabetes mellitus: pharmacology, toxicity, and treatment. Ann Emerg Med. 2001;38(1):68-78.

8. Raz I. Guideline approach to therapy in patients with newly diagnosed type 2 diabetes. Diabetes Care. 2013;36(Supplement 2):S139-44.

9. Nasri H, Rafieian-Kopaei M. Metformin: current knowledge. J Res Med Sci. 2014;19(7):658-64.

10. Kahn SE, Haffner SM, Heise MA, Herman WH, Holman RR, Jones NP, et al. Glycemic durability of rosiglitazone, metformin, or glyburide monotherapy. N Engl J Med. 2006;355(23):2427-43.

11. Abbas A, Blandon J, Rude J, Elfar A, Mukherjee D. PPAR- $\gamma$ agonist in treatment of diabetes: cardiovascular safety considerations. Cardiovasc Hematol Agents Med Chem. 2012;10(2):124-34.

12. Macconell L, Pencek R, Li Y, Maggs D, Porter L. Exenatide once weekly: sustained improvement in glycemic control and cardiometabolic measures through 3 years. Diabetes, Metab Syndr Obes Targets Ther. 2013;6:31-41

13. Tripathi KD. Essentials of medical pharmacology. New Delhi: JP Medical Ltd; 2013.

14. Pandey A, Tripathi P, Pandey R, Srivastava R, Goswami S. Alternative therapies useful in the management of diabetes: a systematic review. J Pharm Bioallied Sci. 2011;3(4):504-12.

15. Association AD. Nutrition recommendations and interventions for diabetes. A position statement of the American Diabetes Association. Diabetes Care. 2008:31(Supplement 1):S61-78.

16. Wang Z, Wang J, Chan P. Treating type 2 diabetes mellitus with traditional Chinese and Indian medicinal herbs. Evid Based Complement Alternat Med. 2013;2013:1-17.

17. Liu JP, Zhang M, Wang W, Grimsgaard S. Chinese herbal medicines for type 2 diabetes mellitus. Cochrane Database Syst Rev. 2002. https:// doi.org/10.1002/14651858.CD003642.pub2.

18. Basch E, Gabardi S, Ulbricht C. Bitter melon (Momordica charantia): a review of efficacy and safety. Am J Health Syst Pharm. 2003;60(4):356-9.

19. Cao H, Polansky MM, Anderson RA. Cinnamon extract and polyphenols affect the expression of tristetraprolin, insulin receptor, and glucose transporter 4 in mouse 3T3-L1 adipocytes. Arch Biochem Biophys. 2007:459(2):214-22.

20. Uebanso T, Arai H, Taketani Y, Fukaya M, Yamamoto H, Mizuno A, et al. Extracts of Momordica charantia suppress postprandial hyperglycemia in rats. J Nutr Sci Vitaminol. 2007;53(6):482-8.

21. Chakravarthy B, Saroj G, Gambhir S, Gode K. Pancreatic beta-cell regeneration-a novel antidiabetic mechanism of Pterocarpus marsupium roxb. Indian J Pharmacol. 1980;12(2):123.
22. Singh PK, Baxi D, Banerjee S, Ramachandran A. Therapy with methanolic extract of Pterocarpus marsupium Roxb and Ocimum sanctum Linn reverses dyslipidemia and oxidative stress in alloxan-induced type I diabetic rat model. Exp Toxicol Pathol. 2012;64(5):441-8.

23. Tastekin B, Pelit A, Polat S, Tuli A, Sencar L, Alparslan MM, et al. Therapeutic potential of pterostilbene and resveratrol on biomechanics, biochemical, and histological parameters in streptozotocin-induced diabetic rats. Evid Based Complement Altern Med. 2018;2018:1-10.

24. Mishra A, Srivastava R, Srivastava SP, Gautam S, Tamrakar AK, Maurya $\mathrm{R}$, et al. Antidiabetic activity of heartwood of Pterocarpus marsupium Roxb. and analysis of phytoconstituents. Indian J Exp Biol. 2013;51(5):363-74

25. Thakur GS, Sharma R, Sanodiya BS, Pandey M, Prasad G, Bisen PS. Gymnema sylvestre: an alternative therapeutic agent for management of diabetes. J Appl Pharm Sci. 2012;2(12):1-6

26. Im R, Mano H, Nakatani S, Shimizu J, Wada M. Aqueous extract of Kotahla Himbutu (Salacia reticulata) stems promotes oxygen consumption and suppresses body fat accumulation in mice. J Health Sci. 2008;54(6):645-53.

27. Stohs SJ, Ray S. Anti-diabetic and anti-hyperlipidemic effects and safety of Salacia reticulata and related species. Phytother Res. 2015;29(7):986-95.

28. Bhatia I, Bajaj K. Chemical constituents of the seeds and bark of Syzygium cumini. Planta Med. 1975;28(08):346-52.

29. Chaudhuri AN, Pal S, Gomes A, Bhattacharya S. Anti-inflammatory and related actions of Syzygium cumin seed extract. Phytother Res. 1990;4(1):5-10.

30. Srivastava H. Paper chromatography of fruit juices. J Sci Ind Res. 1953;12B:363-5.

31. Bhargava K, Dayal R, Seshadri T. Chemical components of Eugenia jambolana stem bark. Current Science 1974.

32. Grover J, Vats V, Rathi S. Anti-hyperglycemic effect of Eugenia jambolana and Tinospora cordifolia in experimental diabetes and their effects on key metabolic enzymes involved in carbohydrate metabolism. J Ethnopharmacol. 2000;73(3):461-70.

33. Lewis Y, Dwarakanath C, Johar D. Acids and sugars in Eugenia jambolana. J Sci Ind Res. 1956;15:280-1.

34. Morton JF. Fruits of warm climates. Winterville, NC: JF Morton; 1987

35. Sacks BN, Brown SK, Stephens D, Pedersen NC, Wu JT, Berry O. Y chromosome analysis of dingoes and southeast Asian village dogs suggests a neolithic continental expansion from Southeast Asia followed by multiple Austronesian dispersals. Mol Biol Evol. 2013;30(5):1103-18.

36. Aybar MJ, Riera ANS, Grau A, Sánchez SS. Hypoglycemic effect of the water extract of Smallantus sonchifolius (yacon) leaves in normal and diabetic rats. J Ethnopharmacol. 2001;74(2):125-32.

37. Annamalai A, Manavalan R. Effect of "Trikatu" and its individual components and piperine on gastrointestinal tracts. Indian Drugs. 1990;27(12):595-604.

38. Johri RK, Thus N, Khajuria A, Zutshi U. Piperine-mediated changes in the permeability of rat intestinal epithelial cells: the status of y-glutamyl transpeptidase activity, uptake of amino acids and lipid peroxidation. Biochem Pharmacol. 1992;43(7):1401-7.

39. Majeed M, Badmaev $V$, Rajendran R. Inventors use of piperine as a bioavailability enhancer patent US Patent 5744161. April 28, 1998.

40. Mang B, Wolters M, Schmitt B, Kelb K, Lichtinghagen R, Stichtenoth $D$, et al. Effects of a cinnamon extract on plasma glucose, $\mathrm{HbA1C}$, and serum lipids in diabetes mellitus type 2. Eur J Clin Invest. 2006:36(5):340-4.

41. American Diabetic Association. Diagnosis and classification of diabetes mellitus. Diabetes Care. 2014;37(Suppl 1):S81-90.

42. Fang L, Lu J-X, Tang J-L, Li L, Lu H-J, Hou X-H, et al. Relationship of plasma creatinine and lactic acid in type 2 diabetic patients without renal dysfunction. Chin Med J. 2009;122(21):2547-53.

43. Vecchio S, Giampreti A, Petrolina V, Lonati D, Protti A, Papa P, et al. Metformin accumulation: lactic acidosis and high plasmatic metformin levels in a retrospective case series of 66 patients on chronic therapy. Clin Toxicol. 2014;52(2):129-35.

44. Ahmad F, Khalid P, Khan MM, Rastogi AK, Kidwai JR. Insulin like activity in (-) epicatechin. Acta diabetologia latina. 1989;26(4):291-300.

45. Hannan J, Ojo O, Ali L, Rokeya B, Khaleque J, Akhter M, et al. Actions underlying antidiabetic effects of Ocimum sanctum leaf extracts 
in animal models of type 1 and type 2 diabetes. Eur J Med Plants. 2015:1-12.

46. Jahromi MF, Ray AB, Chansouria J. Antihyperlipidemic effect of flavonoids from Pterocarpus marsupium. J Nat Prod. 1993;56(7):989-94.

47. George CM, Brujin LL, Will K, Howard-Thompson A. Management of blood glucose with noninsulin therapies in type 2 diabetes. Am Fam Physician. 2015;92(1):27-34.

48. International Expert Committee. International Expert Committee report on the role of the $\mathrm{A} 1 \mathrm{C}$ assay in the diagnosis of diabetes. Diabetes Care. 2009;32(7):1327-34.
49. Khan HA, Sobki SH, Khan SA. Association between glycaemic control and serum lipids profile in type 2 diabetic patients: $\mathrm{HbA1c}$ predicts dyslipidaemia. Clin Exp Med. 2007;7(1):24-9.

50. Association AD. Postprandial blood glucose. Diabetes Care. 2001;24(4):775-8.

\section{Publisher's Note}

Springer Nature remains neutral with regard to jurisdictional claims in published maps and institutional affiliations.
Ready to submit your research? Choose BMC and benefit from:

- fast, convenient online submission

- thorough peer review by experienced researchers in your field

- rapid publication on acceptance

- support for research data, including large and complex data types

- gold Open Access which fosters wider collaboration and increased citations

- maximum visibility for your research: over $100 \mathrm{M}$ website views per year

At BMC, research is always in progress.

Learn more biomedcentral.com/submissions 